\title{
PELATIHAN GURU-GURU PAUD “MELEK” TEKNOLOGI KABUPATEN SIMALUNGUN
}

Training For Early Childhood Teachers "Melek" Technology of Simalungun District

Agus Perdana Windarto ${ }^{\text {* }}$

lin Parlina ${ }^{2}$

Anjar Wanto ${ }^{3}$

*ISTIKOM Tunas Bangsa,

Pematangsiantar, Sumatera Utara, Indonesia

2AMIK Tunas Bangsa, Pematangsiantar, Sumatera Utara, Indonesia

3STIKOM Tunas Bangsa,

Pematangsiantar, Sumatera Utara, Indonesia

*email:

agus.perdana@amiktunasbangsa.ac.id

\begin{abstract}
Abstrak
Pengabdian ini bertujuan untuk meningkatkan pengetahuan dan keterampilan guru-guru PAUD khususnya pembelajaran interaktif berbasis software dan android di Kabupaten Simalungun. Pengabdian ini dilaksanakan selama bulan juli 2019. Kegiatan ini dilaksanakan dalam dua hari, mulai jam 08.00- II.30 WIB (sesi pertama), 14.00- I6.30 WIB (sesi kedua), pada hari Sabtu, 20 dan 27 juli 2019, Lokasi pengabdian bertempat di TK Sandy Putra Pematangsiantar. Sasaran kegiatan ini adalah guru-guru PAUD di kabupaten simalungun. Alasan pemilihan lokasi pengabdian adalah musyawarah dari perwakilan pengelola PAUD mitra di kabupaten simalungun. Bagi guru-guru PAUD disediakan transportasi untuk membawa ke lokasi pengabdian mengingat kegiatan tersebut memiliki dampak positip bagi guru-guru PAUD dalam mendidik anak bangsa di zaman revolusi industri 4.0. Metode yang digunakaan dalam pelaksaannya adalah dengan presentasi/ceramah, diskusi, tanya jawab, dan simulasi/latihan. Hasil dari kegiatan pengabdian ini menunjukkan bahwa dari 40 peserta, guru PAUD mampu menjawab semua soal dengan benar sebanyak 10 soal sebesar $45 \%$ ( 18 peserta) setelah dilakukan pelatihan yang sebelumnya hanya mampu menjawab 9 soal dengan benar sebanyak 13\% (5 peserta) sebelum dilakukannya pelatihan. Oleh karena itu, kedepannya diharapkan dilaksanakan pelatihan lanjutan dengan melibatkan lebih banyak guru-guru PAUD agar dapat memanfaatkan pengetahuan lebih mengoptimalkan dan mengimplementasikan sehingga bisa lebih mudah dicerna oleh peserta didik mereka.
\end{abstract}

Kata Kunci:

Pelatihan

Guru PAUD

Interaktif

Software

Android

\section{Keywords:}

Training

PAUD teacher

Interactive

Software

Android

\begin{abstract}
This community service aims to improve the knowledge and skills of PAUD teachers specifically software-based and android interactive learning in Simalungun District. This dedication was held during July 2019. This activity was carried out in two days, starting at 08.00- II.30 WIB (first session), 14.00- 16.30 WIB (second session), on Saturdays, 20 and 27 July 2019, the location of the service was held in kindergarten Sandy Putra Pematangsiantar. The target of this activity is PAUD teachers in Simalungun District. The reason for the selection of service locations was deliberations from representatives of PAUD partner management in Simalungun District. For teachers, PAUD provides transportation to be taken to the location of the service given that this activity has a responsibility for PAUD teachers in educating the children of the nation in the industrial revolution era 4.0. The method used in the implementation is with presentations / lectures, discussions, questions and answers, and simulations / exercises. The results of this community service activity showed that of the 40 participants, PAUD teachers were able to answer all questions with a number of questions $45 \%$ (I 8 participants) after conducting training which previously were only able to answer 9 questions correctly as many as 13\% (5 participants) before being asked for training. Therefore, in the future it is expected that further training can be carried out by PAUD teachers so that they can utilize knowledge more optimally and implement it more easily by their students.
\end{abstract}




\section{PENDAHULUAN}

Teknologi informasi merupakan teknologi yang menggabungkan komputasi (komputer) dengan jalur komunikasi berkecepatan tinggi yang membawa data, suara, dan video. Mereka merupakan kombinasi dari komputer yang berhubungan dengan saluran komunikasi dengan transmisi data kecepatan tinggi dalam bentuk teks, audio dan video (Nugroho, 2016). Sebagai tenaga pendidik sudah seharusnya mengikuti arus zaman yang sedang mengalir seperti air yang tidak bisa dihindari dan pungkiri. Di zaman teknologi yang serba instan diharapkan untuk tidak gaptek mulai dari kalangan anak- anak, dewasa sampai yang tua. Begitu juga dengan tenaga pendidik, diharapkan untuk melek dalam penggunaan IT sebagai penunjang pembelajaran yang menarik (Asilestari, 2016). Sekolah merupakan tempat anak belajar dan juga bermain. Sesuai tuntutan zaman, sekolah mewajibkan peserta didik menguasai atau memahami penggunaan teknologi informasi, terlebih tingkatan sekolah yang melaksanakan ujian berbasis komputer. Seorang tenaga pendidik di era modern, yang lazim disebut era digital atau era banjir informasi, diwajibkan untuk memahami yang namanya teknologi informasi, dimana sektor pendidikan menjadi salah satu sasarannya khususnya guru PAUD (Nurkholis \& Badawi, 2019). Hal ini berdasarkan dengan Peraturan Pemerintah (PP) Nomor 19 Tahun 2005 tentang Badan Standar Nasional Pendidikan (BSNP) (Indonesia, 2005) ditegaskan bahwa tenaga pendidik harus memiliki kompetensi sebagai agen pembelajaran, sehat jasmani dan rohani, pada jenjang pendidikan dasar dan menengah, serta pendidikan anak usia dini. Arahan normatif tersebut yang menyatakan bahwa tenaga pendidik dalam hal ini sebagai agen pembelajaran menunjukkan pada harapan bahwa guru merupakan pihak pertama yang paling bertanggungjawab dalam pentransferan ilmu pengetahuan kepada peserta didik. Peran Guru PAUD dalam pendidikan anak usia dini merupakan suatu proses perubahan yang menyangkut tingkah laku atau kejiwaan (Maryatun \& Hayati, 20I0). Dalam psikologi belajar, proses berarti cara-cara atau langkah-langkah khusus yang dengannya beberapa perubahan ditimbulkan hingga tercapainya hasil-hasil tertentu. Jadi dapat diartikan proses belajar adalah sebagai tahapan perubahan perilaku kognitif, afektif dan psikomot. Pada dasarnya perkembangan teknologi selalu memberikan dampak positip dan negatif terhadap berbagai kalangan usia mulai usia manula, dewasa, remaja, bahkan anakanak. Hampir sebahagian orangtua membiarkan anakanaknya menggunakan handphone, komputer, PS dan lain sebagainya berjam-jam tanpa memperhatikan dampak negatifnya terutama bagi moralitas atau psikologisnya di kemudian hari. Hal ini berdampak negatif seperti anak menjadi malas, anak menjadi manja, anak cenderung keras dan memberontak kepada orangtua, anak susah beradaptasi dengan lingkungan sekitar, anak jadi lebih tahu tentang orang dewasa sebelum waktunya dan lain-lain. Selain orangtua, tenaga pendidik khususnya guru PAUD adalah orangtua kedua bagi mereka. Metode atau cara mendidik anak pada usia dini, tentu sangatlah berbeda dengan metode atau cara mendidik anak pada masa remaja atau masa setelahnya. Untuk mendidik anak pada usia dini, guru PAUD harus menyajikan materi yang akan kita ajarkan dengan desain yang sangat menyenangkan, salah satunya dengan komputer. Dengan komputer, proses belajar anak akan terasa sangat menyenangkan (Nugroho, 2016). Hal itu tidak bisa dipungkiri lagi, dengan komputer kita bisa memasukkan program-program edukasi yang cocok untuk pendidikan anak pada usia dini. Dengan komputer pula, kita sebagai pendidik akan merasa sangat terbantu dengan penyampaian yang disajikan oleh komputer tanpa meragukan hasil yang kurang optimal. Adanya tampilan gambar warna-warni yang dapat bergerak serta didukung dengan suara atau nyanyian yang riang gembira dapat merangsang anak untuk lebih betah bermain sambil belajar. Karena hanya metode bermain sambil belajarlah yang cocok 
diberikan kepada anak usia dini. Mengingat penggunaan komputer adalah sesuatu yang tidak dapat dihindari pada saat ini dan masa yang akan sekarang, anak harus dikenalkan dengan komputer walaupun ada pengaruh yang tidak baik yang dapat ditimbulkan (Richardo, 2016). Jadi berdasarkan paparan diatas, maka mengajarkan dan mengenalkan komputer pada anak, amat tergantung pada kesiapan pendidik khususnya guru PAUD dalam mengenalkan dan mengawasi anak saat bermain komputer. Oleh karena itu diperlukan pelatihan, workshop dan seminar bagi guru PAUD dimana peran penting mereka dalam pemanfaatan komputer bagi anak sangat dibutuhkan mengingat mereka adalah generasi yang akan mejadi putra-putri terbaik bangsa dimasa yang akan datang. Berdasarkan analisis situasi khalayak sasaran yang telah dikemukakan di atas, permasalahan yang dapat diidentifikasi sebagai berikut :

1. Tidak tersedianya bekal dan pengetahuan teknologi bagi guru PAUD tentang media pembelajaran interaktif berbasis software dan android yang dapat di ajarkan kepada anak didik sebagai upaya pengawasan dalam mengelola teknologi cerdas

2. Minimnya kemampuan guru dalam mengembangkan pembelajaran tentang media pembelajaran interaktif berbasis software yang berkualitas dan memadai di lembaga PAUD

3. Minimnya kemampuan guru dalam merancang perencanaan kegiatan tentang media pembelajaran interaktif berbasis software yang berkualitas dan menyenangkan di lembaga PAUD

4. Minimnya kemampuan guru dalam melakukan evaluasi dan mengembangkan kegiatan tentang media pembelajaran interaktif berbasis software dilembaga PAUD.

Sesuai dengan topik, kegiatan pengabdian pada masyarakat yang dipilih dibatasi pada pembelajaran interaktif berbasis software dan android bagi guru PAUD kabupaten simalungun.

\section{METODOLOGI}

Pelaksanan pengabdian masyarakat ini dilaksanakan selama bulan juli 2019. Kegiatan ini dilaksanakan dalam dua hari, mulai jam 08.00- II.30 WIB (sesi Pertama), 14.00- 16.30 WIB (sesi kedua), pada hari Sabtu, 20 dan 27 juli 2019, Lokasi pengabdian bertempat di TK Sandy Putra Pematangsiantar. Lokasi pengabdian dilakukan sesuai dengan kesepakatan pengelola PAUD di kabupaten simalungun. Peserta kegiatan adalah guruguru PAUD yang berjumlah 40 orang yang mewakili pengelola PAUD masing-masing yang berada di Kabubpaten simalungun. Materi yang disampaikan dalam kegiatan ini adalah tentang pembelajaran interaktif berbasis software dan android serta memberikan contoh secara langsung bagaimana cara penggunaanya. Metode penyampaian dengan cara presentasi dan simulasi yang dilakukan oleh dosen dan mahasiswa prodi Sistem Informasi STIKOM Tunas Bangsa dan prodi Komputerisasi Akuntansi AMIK Tunas Bangsa, Pematangsiantar. Berikut adalah aktivitas serta jadwal pengabdian disajikan dalam Tabell:

Tabel I. Pelatihan pembelajaran interaktif berbasis software dan android

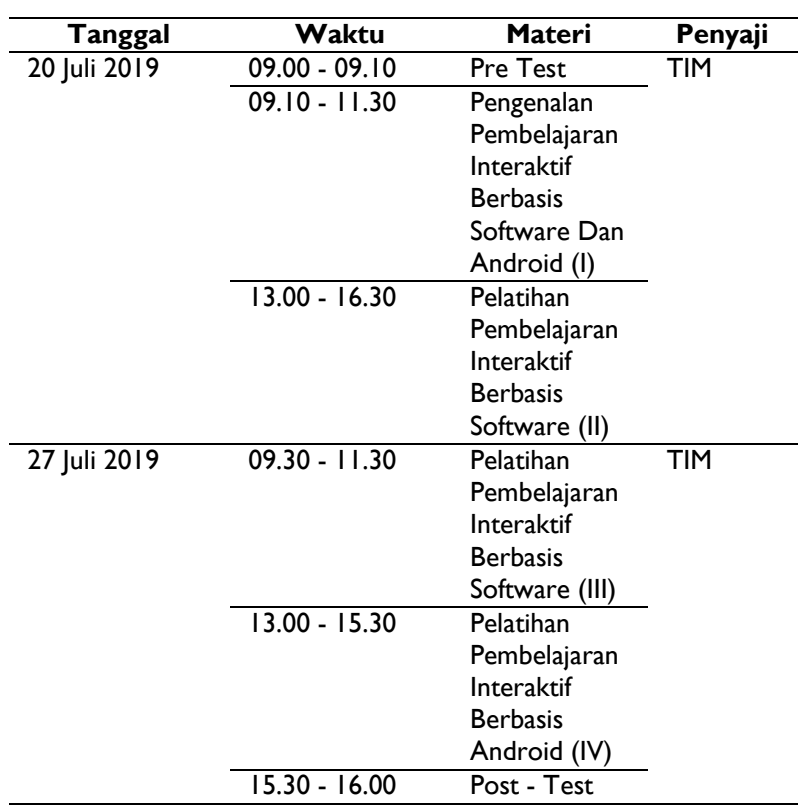


Dari kegiatan pengabdian ini diharapkan solusi permasalahan dapat diselesaikan dengan point-pont sebagai berikut:

1. Terlaksana kegiatan Program Pelatihan media pembelajaran interaktif berbasis software dan android Bagi Guru PAUD yang berlatar belakang pendidikan minimal SMA/Sederajat untuk 20-30 orang.

2. Tersusun Modul Program Pelatihan bagaimana menggunakan media pembelajaran interaktif berbasis software dan android Bagi Guru PAUD mulai dari persiapan hardware, software dan petunjuk penginstalan aplikasi sejumlah 50 Halaman.

3. Tersusun artikel Program Pelatihan media pembelajaran interaktif berbasis software dan android Bagi Guru PAUD yang diterbitkan pada jurnal/majalah nasional/internasional dan seminar nasional pengabdian masyarakat.

Pelaksanaan pengabdian ini disusun secara sistematis pada alur kerja dengan pendekatan partisipatif, penyadaran, pembelajaran (teori dan praktik), serta pendampingan dengan uraian sebagai berikut:

a) Pendekatan Partisipatif

Dilakukan secara koordinatif, melibatkan Tim Pelaksana (Dosen dan mahasiswa) dengan Mitra (Pengelola PAUD) dan guru PAUD.

b) Pendekatan Konseptual

Dilakukan dengan pola pembinaan guru PAUD di wilayah mitra melalui Pelatihan media pembelajaran interaktif berbasis software dan android bagi guru PAUD oleh ahli di bidangnya. Harapannya guru PAUD di wilayah mitra dalam pemanfaatan komputer bagi anak mengingat mereka adalah generasi yang akan mejadi putra-putri terbaik bangsa dimasa yang akan datang.

c) Pendekatan Teori dan Praktik

Dilakukan melalui kegiatan pembelajaran, tatap muka dan penugasan baik teori maupun praktik.
Selanjutnya langkah langkah sistematis yang dilakukan pada kegiatan ini meliputi prosedur:

I) Metode observasi/ studi awal

Dilakukan dengan melakukan survei dan wawancara untuk pengumpulan data-data permasalahan pengelolaan pembelajaran di PAUD pada wilayah kerja mitra. Sasaran adalah pengelola satuan pendidikan PAUD dan peserta didik.

2) Koordinasi

Sesudah ditemukannya fakta-fakta dan permasalahan tentang pengelolaan pembelajaran di PAUD, selanjutnya dilakukan koordinasi dengan mitra di wilayah kerja mitra, sehingga guru memperoleh solusi aspek permasalahan yang prioritas.

3) Sosialisasi Program

Selanjutnya dilakukan pembentukan Panitia Pelaksana yang terdiri dari Tim dosen, tim mahasiswa, mitra, serta relawan yang memiliki kepedulian terhadap kualitas pendidikan secara umum dan pembelajaran khususnya.

4) Pelaksanaan Program

Setelah diperoleh kesepakatan tentang jenis keterampilan (life skill) yang akan diberikan kepada guru PAUD, segera dilakukan pelaksanaan program oleh Tim sesuai SOP.

5) Monitoring

Keberhasilan program ini perlu dilakukan dengan kegiatan monitoring atau pengawasan yang dilaksanakan periodik. Tujuannya adalah agar mendapatkan penjaminan atas kualitas mutu program dan efektivitasnya untuk memenuhi aspek keberlanjutan.

6) Evaluasi

Hasil monitoring menjadi bahan untuk perbaikan pelaksanaan program agar sesuai target yang diharapkan. 


\section{HASIL DAN PEMBAHASAN}

Pelatihan peningkatan pembelajaran interaktif berbasis software dan android bagi guru-guru PAUD di PAUD kabupaten simalungun ternyata mendapat respon yang sangat baik dan positif dari peserta kegiatan. Hal ini tampak pada antusiasme peserta dalam bertanya kepada pemateri. Diantara salah satu peserta bahkan menyatakan minatnya untuk menerapkan metode pembelajaran interaktif berbasis software dan android dalam mendidik anaknya. Berikut beberapa gambar berjalannya proses pelatihan.

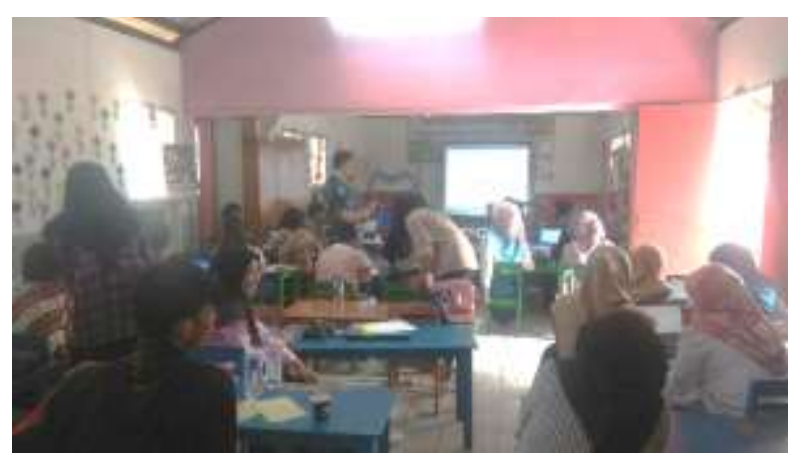

Gambar I. Antusias para guru-guru PAUD dalam mendengarkan paparan

Bagi para guru-guru PAUD yang berhadir, kegiatan pelatihan ini meningkatkan pengetahuan dan kemampuan mereka dalam teknologi informasi khususnya pengetahuan tentang pembelajaran interaktif berbasis software dan android. Hal ini dapat dilihat pada tabel 2 berikut:

Tabel 2. Hasil Evaluasi terhadap kegiatan Pelatihan pembelajaran interaktif berbasis software dan android

\begin{tabular}{|c|c|c|c|c|c|c|}
\hline \multirow{3}{*}{$\begin{array}{c}\text { Kompo } \\
\text { nen }\end{array}$} & \multicolumn{6}{|c|}{ Hasil Test } \\
\hline & \multicolumn{3}{|c|}{ Pre- Test } & \multicolumn{3}{|c|}{ Post- Test } \\
\hline & Jumla & & $\%$ & Juml & & $\%$ \\
\hline \multirow{7}{*}{$\begin{array}{l}\text { Pembelaj } \\
\text { aran } \\
\text { Interaksi } \\
\text { Berbasis } \\
\text { Software } \\
\text { Dan } \\
\text { Android }\end{array}$} & Benar 10 & 0 & 0 & Benar 10 & 18 & 45 \\
\hline & Benar 9 & 5 & 13 & Benar 9 & 9 & 15 \\
\hline & Benar 8 & 8 & 20 & Benar 8 & 5 & 13 \\
\hline & Benar 7 & II & 28 & Benar 7 & 5 & 20 \\
\hline & Benar 6 & 6 & 15 & Benar 6 & 3 & 7,5 \\
\hline & Benar 5 & 5 & 13 & Benar 5 & 0 & 0 \\
\hline & Benar 4 & 5 & 13 & Benar 4 & 0 & 0 \\
\hline
\end{tabular}

Berdasarkan tabel Sejumlah 40 orang peserta yang terdiri guru-guru PAUD mengerjakan pre-test dan post-test wawasan pengetahuan tentang pembelajaran interaktif berbasis software dan android. Berdasarkan hasil tes di atas, dapat diketahui kemajuan pengetahuan peserta test menyangkut materi yang telah disampaikan. Pada sesi pre-test, peserta test maksimal dapat menjawab 9 soal dengan benar sebanyak 13\% (5 peserta) sementara pada sesi post test, peserta mampu menjawab semua soal dengan benar sebanyak 10 soal sebesar 45\% (18 peserta). Hal ini memperlihatkan bahwa yang mereka ketahui tentang pembelajaran interaktif berbasis software dan android kurang memadai sebelum dilaksanakan pelatihan. Berikut grafik evaluasi terhadap kegiatan Pelatihan (pre-test dan post-test)

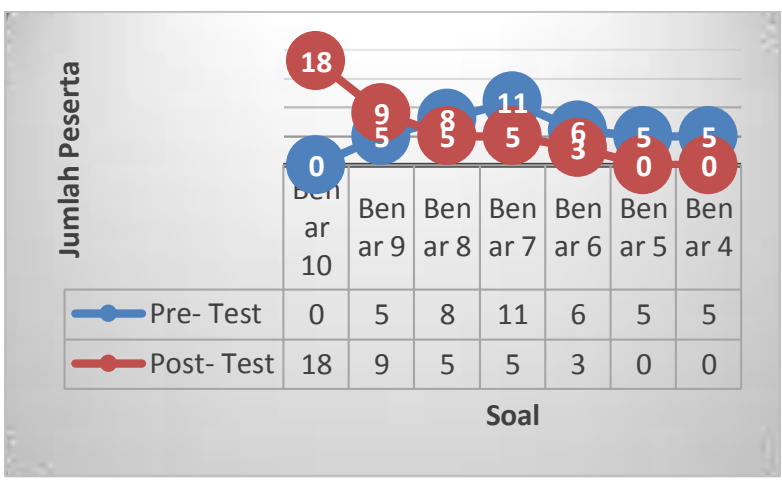

Gambar 2. Grafik evaluasi pre-test dan post test

Pada gambar 2 dapat dijelaskan bahwa setelah pelaksanaan pelatihan tersebut, nampak peningkatan pengetahuan mereka secara signifikan. Terlihat bahwa rata-rata mereka telah memperolah tambahan pengetahuan yang cukup memadai perihal apa yang telah dimaterikan, bahwa pada umumnya mereka telah mampu menjawab seluruh pertanyaan (soal) yang diberikan. Oleh sebab itu diharapkan peserta pelatihan dapat memanfaatkan pengetahuan ini untuk lebih mengoptimalkan, mengimplementasikan, bahan ajar yang selama ini dihasilkan menjadi bahan ajar interaktif, sehingga bisa lebih mudah dicerna oleh peserta didik mereka. 


\section{KESIMPULAN}

Berdasarkan hasil pelaksanaan kegiatan yang telah dilakukan, dapat ditarik beberapa simpulan bahwa pengetahuan guru-guru PAUD tentang tentang pembelajaran interaktif berbasis software dan android masih kurang memadai sebelum dilaksanakanannya pelatihan. Hal ini ditunjukkan dari hasil pre-test. Penyampaian pengetahuan tentang pembelajaran interaktif berbasis software dan android kepada peserta pelatihan dapat meningkatkan pengetahuan sekaligus sebagai stimulant agar guru-guru PAUD lebih kreatif dalam mencari bahan pelajaran. Kegiatan yang dilakukan team dosen dan mahasiswa STIKOM dan AMIK Tunas Bangsa di TK Sandy Putra Pematangsiantar merupakan sebuah kegiatan positif yang bertujuan membekali guru-guru PAUD tentang pengetahuan teknologi khususnya media pembelajaran interaktif berbasis software dan android yang dapat di ajarkan kepada anak didik sebagai upaya pengawasan dalam mengelola teknologi cerdas.

\section{UCAPAN TERIMA KASIH}

Terima kasih yang sebesar-besarnya kami sampaikan kepada Direktorat Riset dan Pengabdian Masyarakat, Direktorat Jenderal Penguatan Riset dan Pengembangan Kementerian Riset, Teknologi, dan Pendidikan Tinggi atas pendanaan yang diberikan sesuai dengan Kontrak Penugasan Pelaksanaan Program Pengabdian kepada Masyarakat Nomor: T/209/LI.3.I/PT.01.03/2019

\section{REFERENSI}

Asilestari, P. (2016). Komputer Interaktif sebagai Media Pengajaran Bahasa Inggris pada Anak Usia Dini. JURNAL PAUD TAMBUSAI, 2(I), 29-45.

Indonesia, P. R. (2005). PERATURAN PEMERINTAH NOMOR 19 TAHUN 2005 TENTANG STANDAR NASIONAL PENDIDIKAN. Retrieved from http://biologi.fkip.uns.ac.id/wpcontent/uploads/2013/08/PP-2005- I9-SNP.pdf
Maryatun, I. B., \& Hayati, N. (20I0). Pengembangan Program Pendidikan Anak Usia Dini. In PENDIDIKAN PROFESI GURU PROGRAM PENGEMBANGAN PENDIDIKAN ANAK (PP. I-76).

Nugroho, N. T. (2016). Pengaruh Penggunaan Teknologi Informasi Terhadap Kinerja Karyawan (Studi Kasus Karyawan STMIK Duta Bangsa). Duta.com, I I (I September 2016), I2-22.

Nurkholis, M. A., \& Badawi. (2019). Profesionalisme guru di era revolusi industri 4.0. In PROSIDING SEMINAR NASIONAL PENDIDIKAN PROGRAM PASCASARJANA UNIVERSITAS PGRI PALEMBANG I 2 JANUARI 2019 (pp. 49I-498).

Richardo, R. (2016). PROGRAM GURU PEMBELAJAR: UPAYA PENINGKATAN PROFESIONALISME GURU DI ABAD 2I. In Prosiding Seminar Matematika dan Pendidikan Matematika (pp. 777785). 